\title{
METHODS OF ROUTINE HAEMOGLOBINOMETRY IN CHILDHOOD: EVALUATION OF COPPER SULPHATE DENSITOMETRY
}

\author{
BY \\ HANAN COSTEFF* \\ From the Beer-Sheva District Health Office, Israel Ministry of Health, Israel
}

(RECEIVED FOR PUBLICATION OCTOBER 26, 1964)

A routine haemoglobin determination is generally recommended as part of the health supervision of infants and children. This is easily done in hospital settings or private practice, but is far more difficult in mass child health supervision among deprived populations. Standard haemoglobinometry methods such as photoelectric colorimetry are poorly adapted to such a purpose because of their expense and their need for trained personnel. The ideal routine haemoglobin examination in settings such as child health surveys in slums or undeveloped regions would permit a provisional diagnosis of anaemia on the spot by relatively untrained personnel, using simple cheap equipment. It would accurately distinguish between anaemia and normality but need not be precise beyond that point.

The determination of whole blood specific gravity in copper sulphate solutions has been described (van Slyke, Phillips, Dole, Hamilton, Archibald, and Plazin, 1950; Phillips, van Slyke, Hamilton, Dole, Emerson, and Archibald, 1950) as having most of the features required for mass screening for anaemia, and has been used for screening blood-bank donors (Heim and Ammon, 1952). It has not yet been standardized or evaluated in children.

This paper reports the standardization and evaluation of the whole blood specific gravity determination as a screening test for anaemia in infancy and early childhood.

\section{Material and Methods}

Copper sulphate solutions were prepared by a modification (Simmons and Gentzkow, 1955) of the method of Phillips and van Slyke (Phillips et al., 1950). Copper sulphate crystals of 'chemically pure' grade were used. Specific gravity of solutions was checked by pycnometry and Westphal balance. Concentration of solutions was measured frequently by iodometric titration of copper

* Present address: Yale University Child Study Center, New Haven, Connecticut, U.S.A. content with $0 \cdot 1 \mathrm{~N}$ sodium thiosulphate solution. Determination of whole blood and plasma specific gravity followed the method of Phillips and van Slyke (Phillips et al., 1950). Haemoglobin was measured by photoelectric colorimetry of cyanmethaemoglobin in a $1: 201$ dilution of blood in Drabkin's solution. The standard solution of cyanmethaemoglobin was matched throughout the study against cyanmethaemoglobin solutions of known iron content. In the study of venous bloods, $1 \mathrm{ml}$. amounts were drawn in $1 \mathrm{mg}$. of double oxalate, and haemoglobinometry was performed on $0 \cdot 1 \mathrm{ml}$. aliquots.

Venous blood in anticoagulant was drawn from 60 infants aged 5-7 months attending child health conferences in the Beer-Sheva area. Haemoglobin, specific gravity of whole blood, and specific gravity of plasma were measured.

The same examinations were performed on the venous blood of 34 children aged 11-14 months in the same setting.

502 consecutive children aged 6 months to 6 years were examined in the same child health conferences. Physical examination was performed, a clinical suspicion of anaemia or its absence was recorded, and a lateral skin puncture was performed on the middle finger with a hypodermic needle. Free blood flow was established in most cases, but minimal squeezing was sometimes necessary. Blood was collected in a $20 \mathrm{c} . \mathrm{mm}$. pipette which was emptied into $4 \mathrm{ml}$. Drabkin's solution for cyanmethaemoglobin colorimetry, and in a microhaematocrit tube from which it was dropped into a copper sulphate solution of specific gravity 1.0458. Specific gravity of blood was read as greater than, equal to, or less than, $1 \cdot 0458$.

Capillary blood in three $20 \mathrm{c} . \mathrm{mm}$. pipettes was collected from 27 children aged 4 months to 5 years, in the same setting and by the same technique. Physical examination was performed first and a clinical prediction of the haemoglobin value was recorded. The bloods underwent one haemoglobin determination by the acid haematin method of Sahli and two separate haemoglobin determinations by photoelectric colorimetry of cyanmethaemoglobin. The first of the two colorimetric determinations was arbitrarily accepted as the 'true' value in calculations of standard error. 
TABLE 1

CORRELATION BETWEEN HAEMOGLOBIN CONCENTRATION AND SPECIFIC GRAVITY OF VENOUS BLOOD

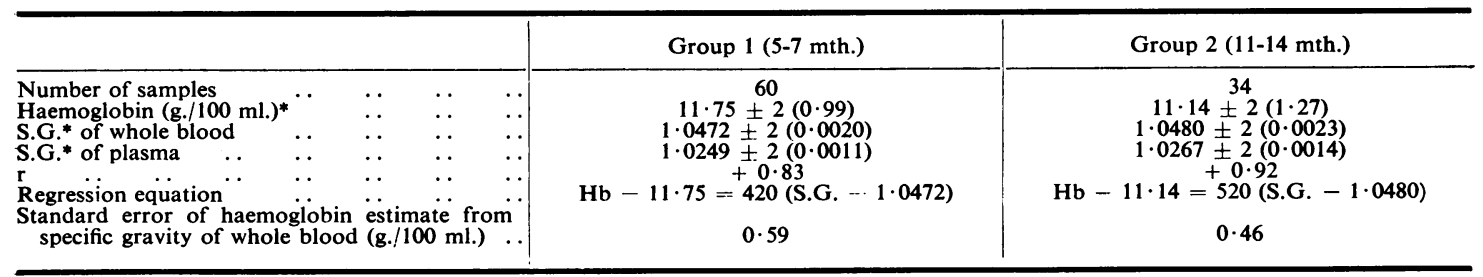

* Recorded as mean \pm 2 (S.D.).

TABLE 2

CORRELATION BETWEEN ANAEMIA AND SPECIFIC GRAVITY SCREENING TEST

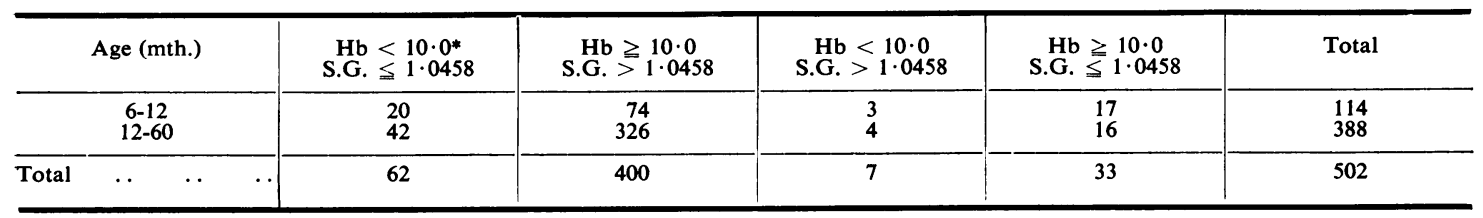

$\mathrm{Hb}$ in $\mathrm{g} . / 100 \mathrm{ml}$.

\section{Results}

The correlation between haemoglobin concentration and specific gravity of venous blood was high in both groups of infants, as shown in Table 1 and in Figs. 1 and 2. The specific gravity of whole blood could be used with small error as an estimate of haemoglobin both in the 5-7-month-old infants and in those of 11-14 months, though the estimates were not identical for the two groups because of a difference in plasma specific gravity.
The effectiveness of a one-drop screening test of whole blood specific gravity as an examination for anaemia (haemoglobin less than $10 \mathrm{~g}$. $/ 100 \mathrm{ml}$.) in 502 children aged 6-72 months is shown in Fig. 3 and in Table 2. Of 69 cases of anaemia, including all but one with haemoglobin values under $9.5 \mathrm{~g} . / 100 \mathrm{ml}$., 62 had specific gravities equal to or less than 1.0458. All the 62 bloods with specific gravities of less than 1.0458 had haemoglobin values of $10.8 \mathrm{~g} . / 100 \mathrm{ml}$. or less, and 53 of them were anaemic. Of the 33

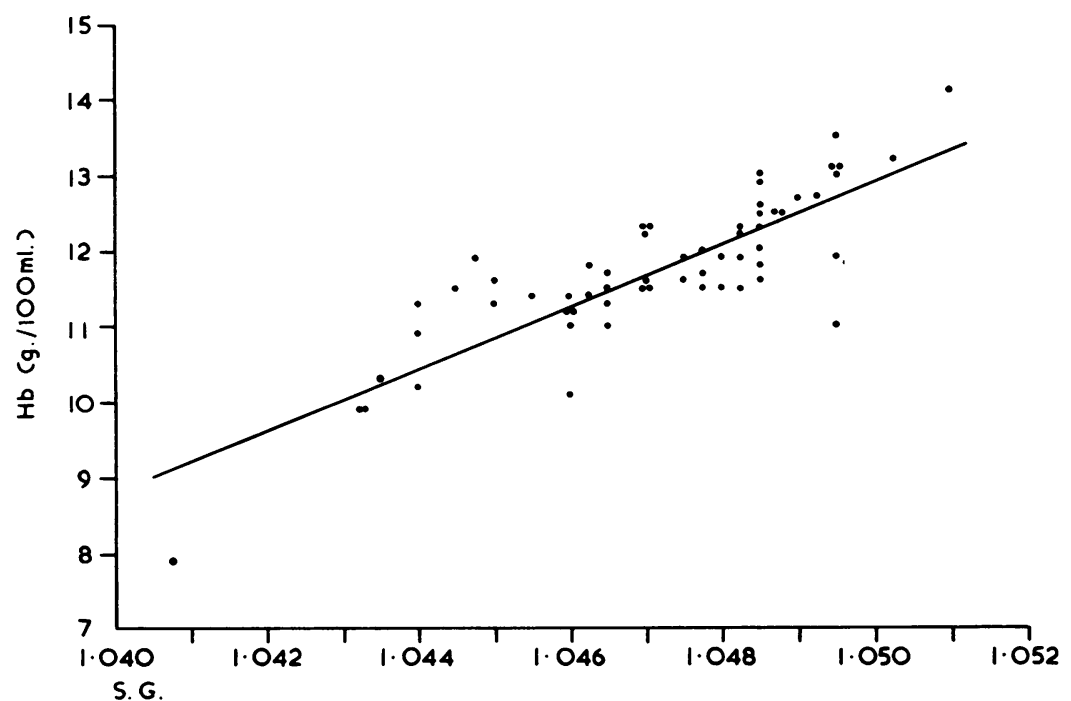

Fig. 1.-Relation between specific gravity and haemoglobin concentration of venous blood in 60 infants aged 5-7 months. 


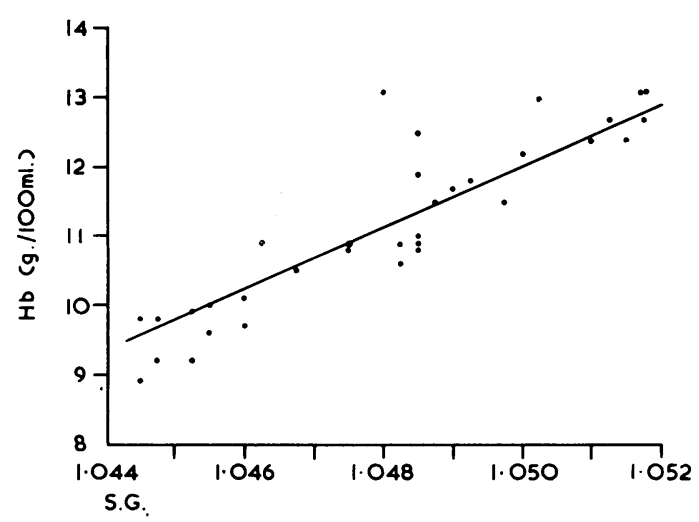

Fig. 2.-Relation between specific gravity and haemoglobin concentration of venous blood in 34 infants aged 11-14 months.

bloods with specific gravities equal to the test solution of $1.0458,9$ were anaemic. Of the 95 bloods with specific gravities equal to or less than $1 \cdot 0458,62$ were anaemic. By comparison, physical examination alone gave a presumptive diagnosis of anaemia in 15 of the 433 children with a normal haemoglobin and in only 18 of the 69 anaemic children. Table 2 shows that the specific gravity is a somewhat more

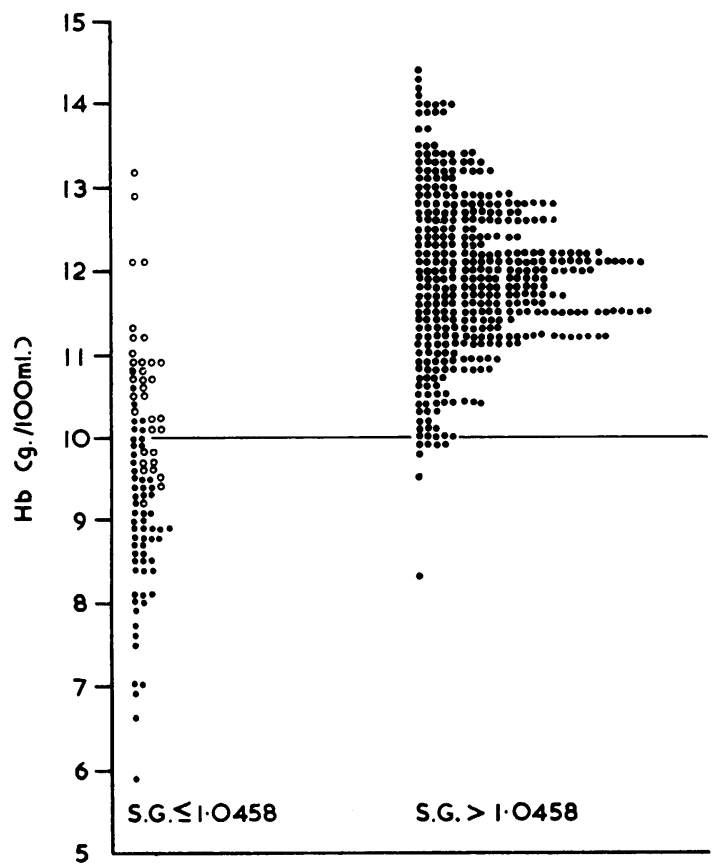

FIG. 3.-Distribution of haemoglobin concentration of capillary blood in 502 children aged 6-60 months. Circles at left represent bloods with S.G. $\leqq 1.0458$. Solid dots at left represent bloods with S.G. $<1.048$. accurate test for anaemia in children over the age of 12 months than in infants. The over-all number of false positive and false negative results indicates a standard error of about $0.71 \mathrm{~g} . / 100 \mathrm{ml}$.

This standard error of estimate may be compared with the standard error of estimate derived for the clinical guess, the Sahli method, and the cyanmethaemoglobin method in a group of 27 children. Table 3 demonstrates that photoelectric colorimetry of cyanmethaemoglobin was somewhat more accurate than the specific gravity determination, the Sahli examination less accurate, and the clinical guess so inaccurate as to be almost valueless.

TABLE 3

RELATIVE ACCURACY OF CAPILLARY HAEMOGLOBIN DETERMINATIONS FROM THE SAME FINGER PUNCTURE

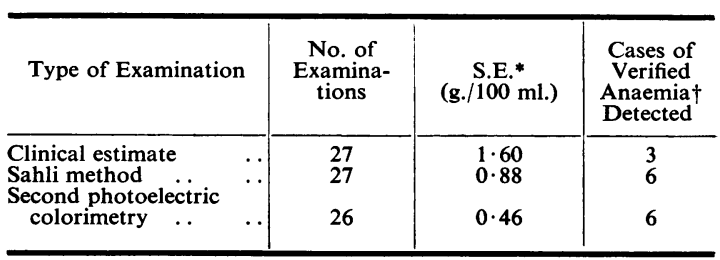

* S.E. = Standard error from 'true value' measured by first photoelectric colorimetry.

† Verified anaemia indicates a haemoglobin of under $10.0 \mathrm{~g} . / 100 \mathrm{ml}$. on the first photoelectric colorimetry. There were 7 such cases.

The different haemoglobin examinations were timed. The one-drop screening examination required a total of 45-60 seconds to perform, including finger-prick. The Sahli examination required about 5 minutes. The various steps of photoelectric colorimetry (pipeting Drabkin's solution, fingerstick, withdrawal, expression, and mixing of blood, reading of solution and standard, and rinsing of tube) required a total of 3-4 minutes per examination.

Stored copper sulphate solutions were repeatedly examined by weighing and thiosulphate titration. The solutions remained stable except for the effect of evaporation. When bottles with mouths of $1 \cdot 0-1 \cdot 5$ $\mathrm{cm}$. diameter remained unstoppered on laboratory benches during a hot dry summer (laboratory temperatures $24^{\circ}-29^{\circ} \mathrm{C}$, relative humidity $30-50 \%$ ) the rate of evaporation ranged from $100 \mathrm{mg}$. to 350 mg. per 24 hours. Evaporation was $15-19 \mathrm{mg}$. per day in loosely stoppered bottles and negligible over a period of months in bottles tightly closed with rubber stoppers.

\section{Discussion}

The results indicate that copper sulphate densitometry is a simple, rapid, and accurate screening test for anaemia. One solution of specific gravity 
1.0458 can be used by semi-skilled personnel to screen for anaemia in the entire 6-month to 6-year age-group at a rate of better than one examination a minute and with less error than the Sahli method in good hands. The total cost is that of one microhaematocrit tube per examination plus 2 to 4 hours of a laboratory technician's time whenever new solution has to be prepared. Since the solution can be prepared in batches of several litres or more, and since each litre suffices for 1,000 examinations, this adds little to the expense. Specific gravity of stock solutions can be checked at preparation and thereafter as needed either by Westphal balance or by iodometric titration with $0 \cdot 1 \mathrm{~N}$ sodium thiosulphate solution. $5 \mathrm{ml}$. copper sulphate solution of specific gravity 1.0458 will be neutralized by 14.38 $\mathrm{ml}$. of the thiosulphate solution.

The standard errors found in the various haemoglobin estimates are compatible with those previously reported. Macfarlane, King, Wootton, and Gilchrist (1948) found an even greater error in the Sahli method than that reported here. The error of photoelectric colorimetry of cyanmethaemoglobin in this study was similar to that reported by King, Bartholomew, Geiser, Ventura, Wootton, Macfarlane, Donaldson, and Sisson (1951) but somewhat greater than that reported earlier by the same workers (King, Gilchrist, Wootton, Donaldson, Sisson, Macfarlane, Jope, O'Brien, Peterson, and Strangeways, 1948) and by Macfarlane et al. (1948). Since their studies were performed on pooled venous blood rather than capillary samples, their smaller errors are not surprising.

The variance of haemoglobin estimate by copper sulphate densitometry is similar to that reported by van Slyke et al. (1950) in a small group of adults, but the regression equation is different, probably because of lower plasma protein concentration in childhood.

For practical purposes evaporation was not a problem in stoppered bottles even in a warm dry climate. Changes of less than 0.0002 in specific gravity of copper sulphate solutions are negligible in calculating haemoglobin, and it would take a total evaporation of $0.44 \%(440 \mathrm{mg}$. of the contents of a $100 \mathrm{ml}$. bottle) to produce this change. Even in unfavourable climates this could be avoided by keeping the stock solution in tightly stoppered bottles and by replenishing the solution in examination bottles every two weeks.

\section{Summary and Conclusions}

The van Slyke 'falling drop' specific gravity measurement of whole blood was correlated with haemoglobin concentration in 94 venous bloods and 502 capillary bloods of children aged 5 months to 6 years. This method was evaluated as an estimate of haemoglobin and as a screening test for anaemia in comparison with acid haematin haemoglobinometry, photoelectric colorimetry of cyanmethaemoglobin, and physical examination. It was found less accurate than photoelectric colorimetry but more accurate than the other methods. In addition the van Slyke method was found to be rapid, cheap, and easy to teach to semi-skilled personnel. It may be recommended as a routine in mass child health supervision.

The Department of Environmental Medicine of the Beer-Sheva Institute for Arid Zone Research provided the facilities for this study. I am grateful to its director Dr. K. Furman, to Anita Levy and Chava Mendel of his staff, and to Louis Fisher of the University of London for their help.

\section{REFERENCES}

Heim, W., and Ammon, G. (1952). Mitteilung uber die Anwendung eines $\mathbf{H b}$-Schnelltestes zu Spenderuntersuchungen. Dtsch. med. Wschr., 77, 51.

King, E. J., Bartholomew, R. J., Geiser, M., Ventura, S., Wootton, I. D. P., Macfarlane, R. G., Donaldson, R., and Sisson, R. B. (1951). Determination of haemoglobin; VIII. Accuracy of methods applied to abnormal bloods. Lancet, 1, 1044.

—, Gilchrist, M., Wootton, I. D. P., Donaldson, R., Sisson, R. B., Macfarlane, R. G., Jope, H. M., O'Brien, J. R. P., Peterson, J. M., and Strangeways, D. H. (1948). Determination of haemoglobin; V. Precision of colorimetric methods. ibid., 2, 563.

Macfarlane, R. G., King, E. J., Wootton, I. D. P., and Gilchrist, M. (1948). Determination of haemoglobin; III. Reliability of clinical and other methods. ibid., 1, 282.

Phillips, R. A., van Slyke, D. D., Hamilton, P. B., Dole, V. P. Emerson, K., Jr., and Archibald, R. M. (1950). Measurement of specific gravities of whole blood and plasma by standard copper sulfate solutions. J. Biol. Chem., 183, 305.

Simmons, J. S., and Gentzkow, C. J. (1955). Medical and Public Health Laboratory Methods, p. 358. Lea and Febiger, Philadelphia.

van Slyke, D. D., Phillips, R. A., Dole, V. P., Hamilton, P. B., Archibald, R. M., and Plazin, J. (1950). Calculation of hemoglobin from blood specific gravities. J. biol. Chem., 183, 349. 